\title{
Oral herpetic infections in children
}

\author{
Payam Forghani ${ }^{1}$, loanna \\ Polichroniadou ${ }^{1}$, Nadezhda Mitova $^{2}$
}

1. Students in Faculty of Dental Medicine, Medical University of Sofia;

2. Department of Pediatric Dentistry, Faculty of Dental Medicine, Medical University of Sofia;

\begin{abstract}
Herpetic gingivostomatitis is a viral infection caused by the herpes simplex virus (HSV), or oral herpes. Young children commonly get it when they are first exposed to HSV. The first outbreak is usually the most severe. HSV can easily be spread from one child to another. The oral manifestations include mucosal vesicle-erosive confluent lesions with a hyperemic base, rough outlines, with uneven and leveled edges, have erythematous margins and possess a pseudomembranous coating. 24 hours later, the vesicles rupture and form painful, small ulcers with a red, elevated halo-like margin and a depressed, yellowish or grayish white central portion. Although HSV gingivostomatitis is a self-limited disease, dehydration may result from poor fluid intake, drooling, and fever. Some children are hospitalized for treatment with parenteral rehydration. Early diagnosis is essential to initiate specific therapy to ensure a reduction in the course of the virus. The antivirus topical therapy is not effective after the 5th day since the onset as the virus is no longer present in the oral cavity. There is a high rate of hospital admissions per symptomatic case compared to that for other common viral infections such as varicella or infectious hepatitis, and thus it is of upmost importance that correct diagnosis is made followed by appropriate treatment.
\end{abstract}

Keywords: herpetic gingivostomatitis, oral viral infection, oral mucosa 


\section{Background}

Herpes virus is a contagious double stranded, Deoxyribonucleic acid (DNA) virus which affects the epithelial cells of the oral mucosa. There exists 8 serotypes of Herpes simplex virus (HSV), however, the two most common are the HSV-1 and HSV-2 strands, both are genetically closely related and share many clinical features. The second serotype, HSV-2, causes neonatal herpetic infection and genital lesions such as genital herpes. The majority of the population have been infected with HSV viridae, however, only $25 \%$ develop the disease.(1)

In childhood the most common viral infections whit oral manifestation are HSV-1, Coxaki virus. There are general symptoms like high fever, general fatigue and weakness and the oral manifestation, dysphagia and dehydration. (2)

Pediatric patients are very susceptible to viral infections, due to their close proximity to other children in kindergartens and schools. Oral viral infections are transmitted by saliva and other body fluids, and are more common in areas of low socioeconomic area where a poor standard of hygiene exists. As a direct consequence of a viral infection, the viral infection causes fever and depression of the immune system. In immunocompromised patients, the symptoms are more severe. In pediatric patients, however, herpetic gingivostomatitis is the most common clinical manifestation of primary herpes simplex virus infection, characterized by fever, extraoral lesions, dysphagia and dehydration.(3)

Protection of viruses is the role of the so called specific factors: cellular and humoral immunity. Tlymphocytes come into contact with the infected cell, make a pore in it and consequently cause cytolysis. Humoral immunity produces antibodies as a result of casual contact with various viruses. However, young children poorly produce $\lg \mathrm{A}(\mathrm{s})$ in the oral cavity resulting in a lower local immunity. Children are immune to herpes infections until the sixth month as there exists a vertical transmission of herpes IgG antibodies to the newborn from the mother.(4) Accordingly, from the sixth month until the age of three years old, children are most susceptible to herpes infections. The eruption of the deciduous teeth and the contact with HSV-1 are the reason for this susceptibility period. $(5,6)$

In the primary infection, the virus ascends through sensory and autonomic nerves, where it persists as latent HSV in neuronal ganglia. Secondary manifestations result from various stimuli such as sunlight, trauma, fever, and stress. Secondary herpetic stomatitis can occur on the palate, gingiva, or on the oral mucosa. (5)

The virus enters the epithelial cells in 5 phases; adsorption, penetration, inhibition of the cell cycle, synthesis of the viral DNA and the final stage is the integration into the host DNA and exit of the new viruses from the cell. Proceeding viral attack, there is a 'balloon degeneration' in the epithelial cell which results in cell lysis and mononuclear cell infiltration around the cell forming nonspecific exudative inflammation and causing vesicle-erosive lesions. There is 1 peak of incidence, from 6 months to 5 years.(7) It rarely affects children under the age of six months. The greater occurrence in children may be justified by the wide dissemination of the virus and due to early exposure to it.(8) Gingivostomatitis is most common in young children, usually under 6 years old, but can also occur in adults. Older people may experience more severe symptoms.

In the oral mucosa, primary herpes simplex virus infection in childhood is usually asymptomatic, although, primary herpetic gingivostomatitis (PHGS) is the most frequent specific clinical manifestation of primary 
herpes simplex infection (HSV-1), occurring in a third of infected pediatric patients.(8) Within the first 24-36 hours, the mouth becomes painful, there is catarrhal hemorrhagic gingivitis, swollen gums, hyper-salivation, difficulty swallowing, regional lymphadenopathy and in some cases conjunctivitis. $(2,6,7)$ Characteristic clinical symptoms are fever, oral lesions, and dysphagia. There is catarrhal hemorrhagic gingivitis, hypersalivation, regional lymphadenopathy and in some cases conjunctivitis. $(9,10)$ Oral mucosal lesions in PHGS are mucosal vesicle-erosive confluent lesions with a hyperemic base, rough outlines, with uneven and leveled edges, have erythematous margins and possess a pseudomembranous coating. (11) The localization of these lesions are the tongue, buccal mucosa and keratinized gingiva. After rupture, these lesions do become painful and irritable to the patient. Diffuse, erythematous, shiny involvement of the gingival and the adjacent oral mucosa may also occur, with varying degrees of edema and gingival bleeding. (12) Although HSV gingivostomatitis is a self-limited disease, dehydration may result from poor fluid intake, drooling, and fever. The clinical features of PHGS can be severely disruptive for the child, affecting child food and liquid intake due to the pain. Some children are hospitalized for treatment with parenteral rehydration. $(13,14)$

Recurrent labial herpes (RLH), recurrent oral herpes infection, ocular herpes infection and cutaneous forms of herpes such as eczema herpeticum are all clinical manifestations of the HSV-1 infection. There is also a risk of bacteremia as a direct complication of herpetic gingiovstomatitis with Kingella Kingae spp. (13)

Primary herpetic gingivostomatitis (PHGS) has to be differentiated clinically from acute necrotising ulcerative gingivitis, recurrent HSV infection, aphtous ulcers, erythema multiforme, teething, allergic stomatitis and ulcers due to chemotherapy. Herpetic stomatitis should be differentiated also from other causes of mouth ulcers especially herpangina, hand, foot and mouth disease, chickenpox and shingles, erythema multiforme and leukaemia. (15-17)

Early diagnosis is essential to initiate specific therapy to ensure a reduction in the course of the virus. The antivirus topical therapy is not effective after the 5th day since the onset as the virus is no longer present in the oral cavity. Normally, the painful oral lesions are present for an average of 12 days. $(18,19)$ Treatment depends on the serotype of the HSV, localization of lesions, immune status and age of the patient. Symptomatic treatment can be made with topical local NSAID's, antiseptics and topical anesthetics. (20) Supportive treatment includes adequate hydration, analgesia, and chlorhexidine mouth baths. Strict indications exist for treatment with oral acyclovir as it is only effective during the prodromal phase of the virus (usually the first 4 days). (21) Treatment of PHGS with oral acyclovir (Zovirax) for gingivostomatitis, and topical pencyclovir (Denovir) for herpes labialis, in specific cases can shorten the duration of all clinical manifestations and is important for a favourable outcome. In any case, the virus genome of HSV-1 persists in the trigeminal ganglia throughout life and the risk for reoccurrence of the virus as tertiary or recurrent herpetic gingovostomatitis always exists. $(22,23)$

\section{Conclusion}

Primary herpetic gingivostomatitis typically occurs in children between six months and five years of age, but it can occur in older children and adolescents. The virus may persist indefinitely in the body due to its retention in the ganglia of the trigeminal nerve in HSV-1. Once a patient is infected with the herpes simplex virus, the infection can recur in the form of herpes labialis with intermittent re-activation occurring throughout life. There is a high rate of hospital admissions per symptomatic case compared to that for other common 
viral infections such as varicella or infectious hepatitis, and thus it is of upmost importance that correct diagnosis is made followed by appropriate treatment.

\section{References}

1. Leventon-Kriss S, Rannon R, Joffe R. Fluorescence and neutralizing antibodies to herpes simplex virus in the cerebrospinal fluid of patients with central nervous system diseases. Isr J Med Sci 1976;12:553-559.

2. Rashkova M, Oral mucosal diseases and syndroms in children and adolescents. (In Bulgarian). Publisher: Direct Services, Sofia 2019, book.

3. Fife KH, Cru M, Packer SC, Mertz GJ, Hill EC, Boone GS. Recurrence and resistance patterns of herpes simplex virus following cessation of $>6$ years of chronic suppression with acyclovir. $J$ Infect Dis 1994;169:133\#4

4. Whitley RJ, Alford CA, Hirsch MS, Schooley RT, Luby JP, Aoki FY, et al. Vidarabine versus acyclovir therapy of herpes simplex encephalitis. N Engl J Med 1986;314:144\#9

5. Ketabchi, A., \& Ahmed, N. (2017). Orofacial Infections. In Maxillofacial Surgery (pp. 14051421). Elsevier. https://doi.org/10.1016/b978-0-7020-6056-4.00092-7

6. Rashkova M. Oral herpes infections in children and adolescents. Ed:SIMEL Sofia 2006, 116p.[In Bulgarian]

7. Rashkova, M. Oral herpetic infections and recurrent aphthae in children. PhD thesis. Sofia 2005

8. Amir J, Straussberg R, Harel L, Smetana Z, Varsano I. Evaluation of a rapid enzyme immunoassay for the detection of herpes simplex antigen in children with herpetic gingivostomatitis. Pediatr Infect Dis J 1996;15:627-629.

9. Amir J, Harel L, Smetana Z, Varsano I. Treatment of herpes simplex gingivostomatitis with aciclovir in children: a randomized double blind placebo controlled study. $\mathrm{Br}$ Med $\mathrm{J}$ 1997;314:1800-1803.

10. Johnson FB, Leavitt RW, Richard DR. Evaluation of the virocult transport tube for isolation of herpes simplex virus from clinical specimens. J Clin Microbiol 1984;20:120-122.

11. Kusushima K, Kimura H, Kino $\mathrm{Y}$, et al. Clinical manifestation of primary herpes simplex type 1 infection in a closed community. Pediatrics 1991;87:152-158.

12. Taieb A, Body S, Astar I, Pasquler PP, Melville J. Clinical epidemiology of symptomatic primary herpetic infection in children. Acta Pediatr Scand 1987;76:128-132.

13. Juretic M. Natural history of herpetic infection. Helv Paediatr Acta 1996;4:356-368.

14. Smetana Z, Dulitzky M, Moshovitz M, Issacsohn M, Seidman D, Leventon-Kriss S. Selected epidemiological features of herpes genitalis in Israel based on laboratory data. Isr J Med Sci 1994;30:375-379.

15. Spruance SL, Rea TL, Thoming C, Tucker R, Saltzman R Boon R. Penciclovir cream for the treatment of herpes simplex labialis-a randomized, multicenter, double-blind placebocontrolled trial. JAMA 1997;277:1374-1379.

16. Amir, J., Harel, L., Smetana, Z., \& Varsano, I. (1999). The Natural History of Primary Herpes Simplex Type 1 Gingivostomatitis in Children. Pediatric Dermatology, 16(4), 259-263.

17. Rocha, Audrey Foster Lefort, et al. "Acute Herpetic Gingivostomatitis Treated with Antiviral and Corticosteroid: a New Therapeutic Protocol." Oral surgery, oral medicine, oral pathology and oral radiology 126.3 (2018): e76.

18. Hale BD, Rendtorff RC, Alker LC, Roberts AN. Epidemic 262 Pediatric Dermatology Vol. 16 No. 4 July/August 1999 herpetic stomatitis in an orphanage nursery. JAMA 1963; 183:1068-1072.

19. Akoi F, Law BJ, Hammond GW. Acyclovir suspension for treatment of acute herpes simplex virus gingivostomatitis in children. A placebo-controlled, double blind trial [abstract]. 33rd Interscience Conference on Antimicrobial Agents and Chemotherapy, 1993:399. 
20. Yagupsky P, Dagan R, Howard CB, Einhorn M, Kassis I, Simu A. Kingella kingae: an emerging course of invasive infections in young children. Clin Infect Dis 1997;24:860- 866.

21. Suremain, N., Guedj, R., Fratta, A., Franclin, A., Loschi, S., Aroulandom, J., \& Carbajal, R. (2019). Acute gingivostomatitis in children: Epidemiology in the emergency department, pain, and use of codeine before its restriction. Archives de Pédiatrie, 26(2), 80-85.

22. Karimi M (2019) A review of gingivostomatitis in children. EC Dental science 18(2): 248-251

23. Amir J, Yagupsky P. Invasive Kingella kingae infection associated with stomatitis in children. Pediatr Infect Dis J 1988;17:757-758.

\section{Corresponding author:}

Nadezhda Mitova,

Department of Pediatric Dentistry,

Faculty of Dental Medicine,

Medical University of Sofia

email: nadia_bm@abv.bg 